\title{
Nitrogen Release Dynamic of Different Coated Urea under Puddle Lowland Rice Cultivation
}

\author{
Rajani* and Ajijit Sen \\ Department of Agronomy, Institute of Agricultural Science, Banaras Hindu University, \\ Varanasi-221005, Uttar Pradesh, India \\ *Corresponding author
}

A B S T R A C T

Keywords

Controlled release fertilizer, Deep placement, Release pattern.

Article Info

Accepted:

23 September 2017

Available Online:

10 October 2017
A research trail was carried out during kharif season 2014-15 to determine release dynamic of nitrogen from different nitrogenous fertilizers and weather effect on release pattern. The result revealed the significant difference between release pattern of nitrogen from coated and uncoated urea. There was no-significant difference between polymer coated urea both single and double layer in $\mathrm{N}$ content of soil just after application upto 23 days. No marked difference in soil $\mathrm{N}$ content was noticed because of steady temperature during experimentation. Coated urea fertilizers released $\mathrm{N}$ with slower rate than Urea supergranule, hence availability of nitrogen was there, for quite longer period.

\section{Introduction}

Controlled or Slow release fertilizers have been developed to counterpoise disadvantages of conventional urea. Urea in soil solubilise within 7-10 days after its application. Urea applied at sowing/ planting when need of nitrogen is less ensuing wastage of nutrient or fertilizer and in the succeeding growth stages when its requirement increases, plant suffer with nutrient stress. Controlled release fertilizer (CRF) is designed manure that releases active fertilizing nutrients in a controlled manner and delayed it in synchrony with the sequential needs of plants for nutrients (Shaviv, 2005). The widespread agriculturally important slow or controlled release fertilizers are coated urea such as sulphur coated urea (SCU), Neem coated urea (NCU), polymer coated urea, nitrification inhibitors and urease inhibitor. Trials conducted by KRIBHCO showed the superiority of neem emulsion coating urea over prilled urea. These emulsion coatings also improves the shelf life of urea and sustains nitrogen in the soil for a very long time resulting in better yields for farmers and also have pesticide properties. Reviews regarding agronomic responses to neem coated urea (NCU) are available in Prasad et al., (2005, 2007). The most promising for widespread agricultural use are polymer coated urea which can be designed to release nutrient in a controlled manner (Baligar, 
2015). Temperature and moisture are two climatic factors that affect the rate, pattern and duration of release of nitrogen from coated urea (Fujinuma et al., 2009; Shaviv, 2005).

Polyolefin-coated fertilizer (POCF) is one of the polymer coated urea developed in Japan that shows highly controlled nutrient-release characterized by temperature. The release dynamic of nutrient from coated urea also affected by coating thickness, size of granule and water permeability. Numerous researches have been done on slow release fertilizers and polymer coated urea for analyzing its use efficiency. Numbers of polymer coated urea were tested in laboratory to study release pattern, rates and release duration of urea from particles. The outcomes indicated that sulfur, urease inhibitors and polymer coated urea released nitrogen for longer time and synchronized with the crop nutrient demand (Kaneta et al., 2010). However, at present least information is available on nutrient release dynamic of coated urea applied in different cropping season. Hence the present study is aimed on N-release dynamics of coated urea in puddled lowland cultivation.

\section{Materials and Methods}

A research trail was carried out in pots at Agriculture Farm of BHU, Varanasi. Surface soil of pot was collected, bulked, air-dried and ground to pass a 2-mm sieve.

Soil was sandy clay loam with $\mathrm{pH} 7.4$ (1:2.5 soil: water), $0.38 \%$ organic carbon (Walkey and black's method, 1934), $179 \mathrm{~kg} \mathrm{ha}^{-1}$ (Subbiah and Asija's Alkaline permanganate method 1956), $18 \mathrm{~kg} \mathrm{ha}^{-1}$ (Olsen et al., 1954) and $199.6 \mathrm{~kg} \mathrm{ha}^{-1}$ (Ammonium acetate Method)NPK respectively. Circular open bottom cemented pots were buried in field and $100 \%$ recommended dose of fertilizers (DAP 2.5g and MOP 2.0g per pot) were uniformly mixed in soil and then puddled.
The pot experiment consisting 5 treatments each replicated 4 times in Randomized Complete Block Design (RCBD). NDR-97, a short duration rice variety was selected as test crop. Treatments in the experiment were $\mathrm{U}_{0^{-}}$ Urea Supergranule (USG), U $\mathrm{U}_{1}$-Polymer coated urea (single layered), $\mathrm{U}_{2}$-Polymer coated urea (double layered), $\mathrm{U}_{3}$-Neem coated urea (NCU) and $\mathrm{U}_{4}$-Sulfur coated urea (SCU). Coated urea fertilizers $(2 \mathrm{~g})$ were $7.5 \mathrm{~cm}$ deep placed in the center of four rice hills at a week after transplanting.

Neem coated urea was purchased from market and sulfur coated urea was prepared by coating urea particle with sulfur powder in 3:1 ratio. Polymer coated urea was prepared in laboratory by coating urea granule with polylactic acid solution. Soil samples were taken and analyzed at 3 days interval after deep placement of coated urea upto 41 days after application. The analysis of nitrogen was completed by Alkaline Permanganate method.

\section{Results and Discussion}

The nitrogen status of soil with different coated urea and urea supergranules were recorded at 3 days interval after application (Figure 1). The data clearly revealed that $\mathrm{N}$ status of soil analyzed at 3 days interval markedly increased till maturity of crop with application of polymer coated urea, while plant showed deficiency in later stage of growth with conventional urea.

Initially polymer coated urea (PCU) released $\mathrm{N}$ slowly upto a week thereafter rapid release was noticed, whereas in case of urea supergranule most of $\mathrm{N}$ was release within 20 days after application. These finding are in close conformity with those of Gandeza et al., (1991) and Zvomuya et al., (2003). Dissolution of nutrient in coating depends on coating thickness, size of urea particles and permeability of water into the coating (Shaviv et al., 2003). 
Table.1 Weekly meteorological data of Varanasi during experiment period (June to October, 2014)

\begin{tabular}{|c|c|c|c|c|}
\hline \multirow[t]{2}{*}{ Month\& Date } & \multicolumn{2}{|c|}{ Temperature $\left({ }^{0} \mathrm{C}\right)$} & \multirow[t]{2}{*}{ Rainfall (mm) } & \multirow[t]{2}{*}{ Evaporation (mm) } \\
\hline & Max. & Min. & & \\
\hline June $04-10$ & 43.4 & 28.3 & 0.0 & 7.0 \\
\hline $11-17$ & 37.6 & 28.5 & 5.4 & 7.7 \\
\hline $18-24$ & 37.7 & 27.7 & 42.9 & 5.1 \\
\hline $25-01$ & 38.8 & 28.5 & 12.8 & 6.9 \\
\hline 02-08 & 33.9 & 26.6 & 65.9 & 4.2 \\
\hline $09-15$ & 36.7 & 28.7 & 0.0 & 5.4 \\
\hline $16-22$ & 32.8 & 26.8 & 261.5 & 2.8 \\
\hline $23-29$ & 33.3 & 26.6 & 4.6 & 3.3 \\
\hline $30-05$ & 32.8 & 27.7 & 46.0 & 4.4 \\
\hline August 06-12 & 32.9 & 26.4 & 142.7 & 3.3 \\
\hline $13-19$ & 23.6 & 27.6 & 42.4 & 2.8 \\
\hline $20-26$ & 35.1 & 27.5 & 14.0 & 4.4 \\
\hline $27-02$ & 33.0 & 27.1 & 6.5 & 4.6 \\
\hline Sept. 03-09 & 32.7 & 26.4 & 34.9 & 3.0 \\
\hline $10-16$ & 31.9 & 25.8 & 11.0 & 3.1 \\
\hline $17-23$ & 33.3 & 26.0 & 13.7 & 3.4 \\
\hline $24-30$ & 33.4 & 24.3 & 2.1 & 4.1 \\
\hline Oct $\quad 01-07$ & 32.2 & 24.2 & 0.0 & 3.1 \\
\hline
\end{tabular}

Fig.1 Release dynamic of nitrogen from different coated urea

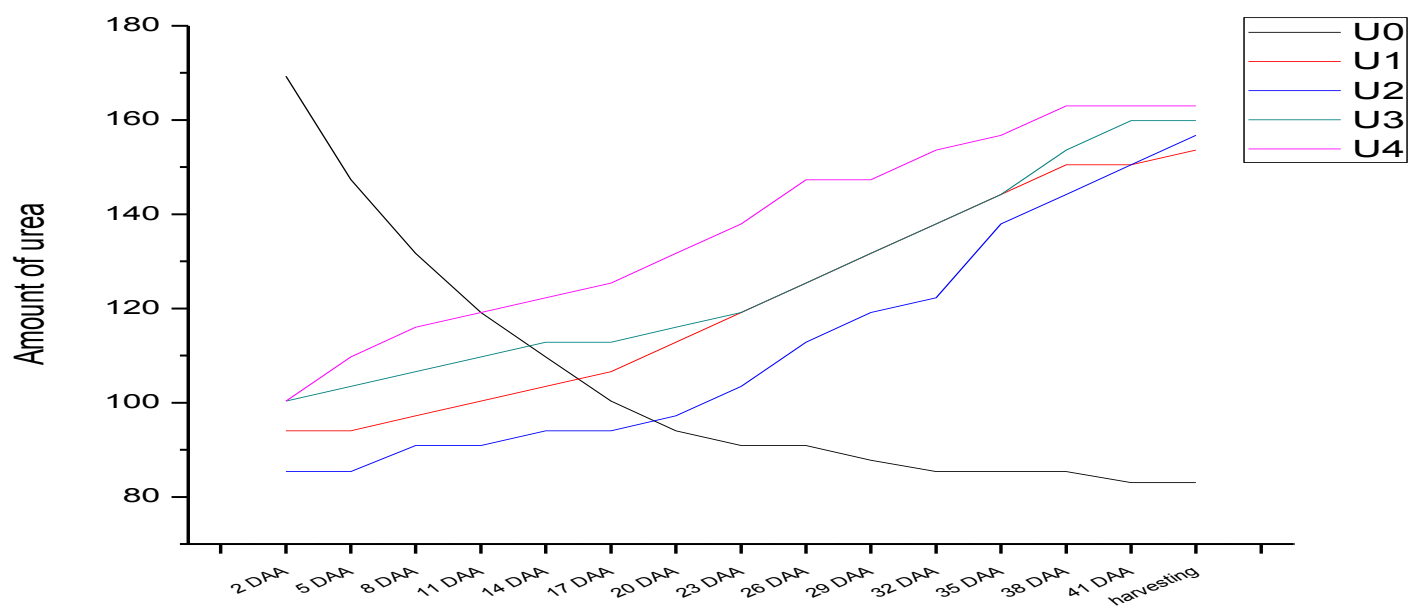

$\mathrm{U}_{0}=$ Urea Supergranule $\mathrm{U}_{1}=$ Polymer coated urea (Single layer)

$\mathrm{U}_{2}=$ Polymer coated urea (Double layer) $\mathrm{U}_{3}=$ Neem coated urea

$\mathrm{U} 4=$ Sulfur coated urea DDA= Days after Application

Nitrogen release from fertilizers generally influenced by weather elements specially temperature and soil moisture content. There was no marked difference in temperature 
during the experimentation, therefore no fluctuation was noticed in rate of nitrogen release with respect to temperature, but slight decline was noticed during 21-26 days after application (DAA) due to decrease in temperature; after which sharp increase in $\mathrm{N}$ content of soil found in the observation taken at 26, 29, 32 and 35 DAA due to higher soil temperature in respective week. This supports the finding of Wang et al., (2011).

Moisture is another factor that affects the rate, pattern and duration of release of nitrogen from coated urea (Fujinuma et al., 2009; Shaviv, 2005) (Table 1). However, since the trail was conducted under irrigated condition, the effect of moisture remained neutral for all the treatments. It concluded from present investigation that coated urea delay nitrogen release for longer time and help in controlling release pattern in synchrony with plant nutrient demand ensures better uptake of nutrient by plant root and assimilation of most of nutrient for sustainable crop production.

\section{References}

Baligar, V.C., 2015. Nitrogen use efficiency in plant: An overview. In: Rakshit, Singh \& Sen (eds.) Nitrogen Use Efficiency: from Basics to Advances. Doi: $\quad 10.1007 / 978-81-322-2169-2-1$ Springer India, 1-14.

Fujinuma, R., Balster, N.J. and Norman, J.M. 2009. An improved model of nitrogen release for surface-applied controlledrelease fertilizer. Soil Sci. Soc. Am. J. 73:2043-2050.

Gandeza, A.T., Shoji, S. and Yamada, I.
1991. Simulation of crop response to polyolefin coated urea: I. Field dissolution. Soil Sci. Soc. Amer. J. 55: 1462-1467.

Kaneta, Y., Awasaki, H. and Murai, T. 2010. The non-tillage rice culture by single application of fertilizer in a nursery box with controlled-releases fertilizer. Jap $J$ Soil Sci Plant Nutr. 65:385-391.

Prasad, R., 2005. Research on nitrification inhibitors and slow- release nitrogen fertilizers in India: A review. P. Natl. A. Sci. India BLXXV: 149-157.

Prasad, R., 2007. Nitrogen in Indian Agriculture. In: Abrol, Raghuram and Sachdev (eds.), Agriculture Nitrogen Use and Its Environmental Implications. IK International Publishing, New Delhi. Pp. 29-54.

Shaviv, A., 2005. Controlled release fertilizers. In IFA International Workshop on Enhanced-Efficient Fertilizers. Frankfurt, Germany.

Shaviv, A., Raban, S. and Zaidel, E. 2003. Modeling controlled nutrient release from polymer coated fertilizers: diffusion release from single granules. Environ. Sci. Technol. 37(10): 22512256.

Wang, S., Alva, A.K., Li, Y. and Zhang, M. 2011. A Rapid Technique for Prediction of Nutrient Release from Polymer Coated Controlled Release Fertilizers. Open Journal of Soil Science. 1: 40-44.

Zvomuya, F., Rosen, C.J., Russelle, M.P. and Gupta, S.C. 2003. Nitrate leaching and nitrogen recovery following application of polyolefin-coated urea to potato. $J$. Environ. Qual. 32:480-489.

\section{How to cite this article:}

Rajani and Ajijit Sen. 2017. Nitrogen Release Dynamic of Different Coated Urea under Puddle Lowland Rice Cultivation. Int.J.Curr.Microbiol.App.Sci. 6(10): 2638-2641. doi: https://doi.org/10.20546/ijcmas.2017.610.311 